\title{
Occurrence, distribution, and ecological-health risks of selected antibiotics in coastal waters along the coastline of China
}

\author{
Jian $\mathrm{Lu}^{\mathrm{a}, \mathrm{b}, *}$, Jun $\mathrm{Wu}^{\mathrm{c}}$, Cui Zhang ${ }^{\mathrm{a}}$, Yuxuan Zhang ${ }^{\mathrm{a}}$, Yichen Lin ${ }^{\mathrm{a}}$, Yongming Luo ${ }^{\mathrm{a}}$ \\ a Key Laboratory of Coastal Environmental Processes and Ecological Remediation, Yantai Institute of Coastal Zone Research, Chinese Academy of Sciences, Yantai, Shandong 264003, China \\ b Center for Ocean Mega-Science, Chinese Academy of Sciences, Qingdao, Shandong 266400, China \\ c Qinghai Institute of Salt Lakes, Chinese Academy of Sciences, Xining, Qinghai 810008, China
}

\section{H I G H L I G H T S}

- Seven target antibiotics were detected in coastal waters along Chinese coastline.

- Total concentrations of target antibiotics were in the range of $389-3302.3 \mathrm{ng} / \mathrm{L}$.

- Veterinary, anthropogenic and mixed sources affected the distribution of antibiotics.

- Norfloxacin and sulfamethoxazole exerted high ecological risks.

- Antibiotics posed very low health risks for adults and children.

\section{A R T I C L E I N F O}

\section{Article history:}

Received 30 May 2018

Received in revised form 29 June 2018

Accepted 8 July 2018

Available online 23 July 2018

\section{Keywords:}

Antibiotics

Ecological risks

Health risk assessment

China coastal waters

\section{G R A P H I C A L A B S T R A C T}

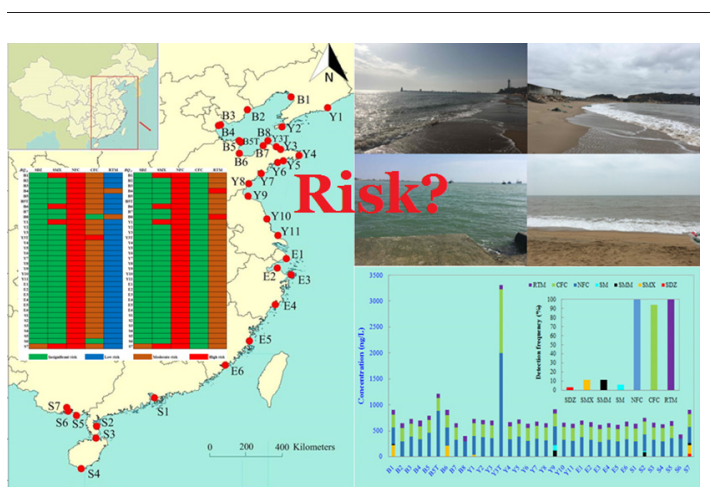

\begin{abstract}
A B S T R A C T
Information on ecological and health risks posed by antibiotics in coastal waters at continental or national scale is limited although antibiotics have continuously entered the natural environments due to extensive usage for human beings and animals. This study collected coastal water samples along nearly $18,000 \mathrm{~km}$ of coastline of China to investigate the distribution, possible sources, and potential ecological-health risks of antibiotics. Only 7 out of 13 target antibiotics were detected in coastal water samples. Total concentrations of antibiotics ranged from 389 to $3302.3 \mathrm{ng} / \mathrm{L}$. Norfloxacin (NFC), roxithromycin (RTM), and ciprofloxacin (CFC) were the most frequently detected antibiotics, with the maximal concentrations of 1990, 1230, and $109 \mathrm{ng} / \mathrm{L}$, respectively. Antibiotics in coastal waters might be affected by three possible factors including veterinary-drug sources, anthropogenic sources, and mixed sources. Detected NFC and sulfamethoxazole (SMX) exerted high ecological risks in the short and long terms. CFC posed moderate short-term risks but insignificant long-term risks for aquatic organisms. RTM exerted low short-term risks while it posed moderate risks in the long term. Antibiotics exerted very low cancer risks and negligible non-cancer risks for both adults and children at all sampling sites. Health risks for children posed by antibiotics were generally higher than those for adults. Antibiotics in coastal waters of China still need effective control due to potential ecological-health risks they pose.
\end{abstract}

(c) 2018 Elsevier B.V. All rights reserved.

\footnotetext{
* Corresponding author at: Key Laboratory of Coastal Environmental Processes and Ecological Remediation, Yantai Institute of Coastal Zone Research, Chinese Academy of Sciences, Yantai, Shandong 264003, China.

E-mail address: jlu@yic.ac.cn (J. Lu).
} 


\section{Introduction}

Antibiotics, an important class of pharmaceuticals, have been extensively used for preventing and treating bacterial infections as well as promoting yields of animal husbandry and aquaculture (Chen et al., 2015a, 2015b; Qiao et al., 2018; Zhang et al., 2015). The consumed antibiotics continuously enter the natural environments through different pathways especially including excretion (urine and feces) by human beings and animals (Carvalho and Santos, 2016). These compounds reach aquatic environments via direct effluent discharge of wastewater/sewage treatment plants, runoff and leaching from manure-fertilized farmlands, landfill leachate, leakage of sewer and manure storage tanks, sewage disposal, and other sources (Carvalho and Santos, 2016). Marine environments serve as an important sink of antibiotics which are transported into coastal waters mainly through riverine inputs (Zheng et al., 2012) and effluents of wastewater/sewage treatment plants (Minh et al., 2009). The residues in seawater also have caused antibiotic pollution in different countries (Minh et al., 2009; Nödler et al., 2014).

China is the largest producer and consumer of antibiotics in the world (Zhu et al., 2013), with the estimated production of 210,000 tons in 2007 (Hvistendahl, 2012) and 248,000 tons in 2013 (Zhang et al., 2015). Approximately 162,000 tons of antibiotics were used in China in 2013, with animal consumption accounting for about $52 \%$ of used antibiotics and three types of antibiotics including fluoroquinolones, sulfonamides, and macrolides contributing to $48 \%$ of total usage (Zhang et al., 2015). Therefore, wide usage of antibiotics in China has caused frequent detection of these chemicals in various environmental matrices (Chen et al., 2015b; Sun et al., 2017; Zhu et al., 2013), food (Li et al., 2017), biota (Chen et al., 2015a; He et al., 2016), and human (Li et al., 2017; Liu et al., 2017; Wang et al., 2017).

Antibiotic residues have triggered unexpected consequences (Carvalho and Santos, 2016; Chen et al., 2017; Liu et al., 2017; Wang et al., 2017; Zhu et al., 2013). These compounds and their by-products may be pseudo-persistent owing to a cycle of bioaccumulation, partial transformation, and deposition in soils and waters (Carvalho and Santos, 2016). Antibiotic resistance induced by the abuse of these agents might be a huge threat to human beings and animals (Gross, 2013). Residues of various antibiotics in aquatic environments exert potential risks to the aquatic ecosystems and organisms (Carvalho and Santos, 2016; Chen et al., 2015b). Bioaccumulation of antibiotics might induce the potential risks to the marine organisms. Fluoroquinolones, sulfonamides, and trimethoprim have been reported to bio-accumulate in wild marine fish or fish from marine aquaculture farms (Chen et al., 2015a; Liu et al., 2018). Several veterinary antibiotics such as oxolinic acid and oxytetracycline were observed to bio-accumulate in the blue mussel (Bris and Pouliquen, 2004). Moreover, antibiotic exposure may also pose potential health risks to human beings (Liu et al., 2017; Wang et al., 2017).

Coastal regions are critical for social sustainability all over the world (Zhu et al., 2017), especially for China since coastal regions cover $13 \%$ of the total landmass and contain $40 \%$ of population in China (Meng et al., 2017). Coastal regions are not only the critical ecologically fragile regions but also the most important regions with the fastest developing pace and the extensive anthropogenic activities (Zhu et al., 2017; Meng et al., 2017). Water pollution has become a crucial stress affecting the critical ecologically fragile regions such as the coastal zone due to the rapid economic development and extensive anthropogenic activities (Wang et al., 2018; Wen et al., 2018; Zhu et al., 2017). Although some research work focuses on the antibiotics in waters of some local bays or gulfs of China including Bohai Bay, Beibu Gulf, Jiaozhou Bay, Laizhou Bay, Yantai Bay, Liaodong Bay, and Shenzhen Bay (Zhang et al., 2013; Zou et al., 2011; Zheng et al., 2012), comprehensive information on occurrence and the ecological-health risks of these chemicals at continental or national scale is still rare. Additionally, both long-term and short-term ecological risks were not figured out while health risks were not assessed in these investigations. Considering that fluoroquinolones, sulfonamides, and macrolides are the widely-used antibiotics in China, this study performed the field sampling and analyzed 13 target antibiotics belonging to these three types in the coastal water samples. The final aim of this study is to provide initial insight on the occurrence, short-term and long-term ecological risks, and health risks of antibiotics in coastal waters along nearly $18,000 \mathrm{~km}$ of Chinese coastline, which will build a basis for water quality management and pollution control of antibiotics in coastal regions at continental scale.

\section{Materials and methods}

\subsection{Standards, chemicals, and reagents}

Three types of antibiotics including fluoroquinolones, sulfonamides, and macrolides were analyzed by this study. Sulfonamide antibiotics included sulfadiazine (SDZ), sulfamethoxazole (SMX), sulfamethazine (SMZ), sulfamonomethoxine (SMM), sulfachinoxalin (SCX), sulfadimethoxine (SDM), sulfameter (SM), and sulfaclozine (SCZ). Fluoroquinolone antibiotics comprised norfloxacin (NFC), ofloxacin (OFC), ciprofloxacin (CFC), and enrofloxacin (EFC). Macrolide antibiotics only included roxithromycin (RTM). All antibiotic standards were purchased from Dr. Ehrenstorfer GmbH (Germany). Three isotope-labeled internal standards (sulfamethazine-d4, sulfadimethoxine-d6, and enrofloxacind5) were also obtained from Dr. Ehrenstorfer GmbH (Germany). Stock solutions of target antibiotics except ciprofloxacin were prepared using methanol with concentration of $100 \mathrm{mg} / \mathrm{L}$ and stored at $-20^{\circ} \mathrm{C}$, and same to stock solutions of internal standards. Ciprofloxacin was dissolved in $1 \%$ o $(\mathrm{v} / \mathrm{v})$ formic acid/methanol solution to reach the final concentration of $100 \mathrm{mg} / \mathrm{L}$. Fresh stock solution was prepared biweekly. Mixture working solution of target antibiotics was prepared every week by using methanol to dilute the stock solutions and stored at 4 ${ }^{\circ} \mathrm{C}$ in darkness, and same to mixture working solution of internal standards.

\subsection{Sample collection, preparation and analysis}

Surface coastal water samples were collected in November of 2017. All coastal water samples were collected from 32 sites along Chinese coastline involving 4 representative coastal regions in China shown as Bohai Area (B1-B8), East China Sea Area (E1-E6), South China Sea Area (S1-S7), and Yellow Sea Area (Y1-Y11) (Fig. 1). Additional marine aquaculture tail water samples were taken from Sites B5 and Y3 and denoted as B5T and Y3T for comparison. Sampling locations covered the maricultural zones, bathing beaches, estuaries, and ports. Surface coastal water was collected at the sampling site that was about 2-3 m off the coast using pre-cleaned amber glass bottle attached on a sampling rod. For each sampling site, water sample with volume of $30 \mathrm{~L}$ made by mixing 6 sub-samples with volume of $5 \mathrm{~L}$ was used as the representative sample of the sampling site. Each sub-sample was collected along the coastline of the target sampling site with the distance interval of $5 \mathrm{~m}$. Coastal water samples were placed in the cooler and transported back to the laboratory as soon as possible for further analysis.

Salinity of each sample was measured using a portable refractometer (LH-Y100, Lohand Biological, China). Total nitrogen (TN) and total phosphorus (TP) were analyzed by a continuous flow analyzer (AutoAnalyzer III, Seal, Germany). Total organic carbon (TOC) was measured with a total organic carbon analyzer (TOC-VCPH, Shimadu, Japan). The water samples with volume of $1 \mathrm{~L}$ were filtered through $0.45 \mu \mathrm{m}$ membrane filters (Pall Life Sciences, Ann Arbor, MI, USA), and spiked with internal standard solution to make the final concentration of internal standards in water samples reach $100 \mu \mathrm{g} / \mathrm{L}$. Solid phase extraction was used for sample preparation. Oasis hydrophilic-lipophilic balance (HLB) cartridges $(6 \mathrm{~cm} / 500 \mathrm{mg}$ ) purchased from Waters Corporation (Milford, MA, USA) were used for extracting target antibiotics from the coastal water samples. The detailed information on extraction procedure referred to Huang et al. (2013). The final extracted samples 


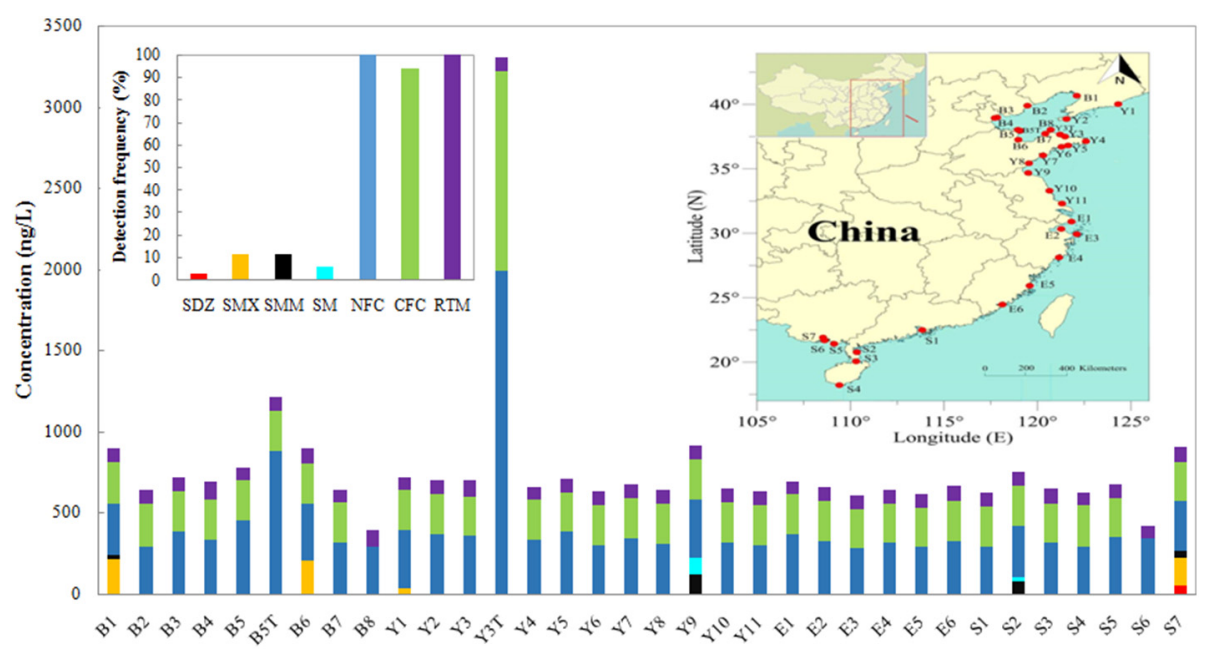

Fig. 1. Distribution, concentrations, and detection frequencies of target antibiotics in coastal waters.

were analyzed using HPLC-MS/MS. Instrument and analysis procedures used by this study were same with Huang et al. (2013).

\subsection{Correlation analysis and source apportionment}

Pearson correlation analysis was performed to investigate the potential relationship between the target antibiotics and water quality parameters including salinity, TOC, TN, and TP. All data were processed using SPSS 19.0 (IBM, New York, USA).

This study also adopted positive matrix factorization (PMF) model to discuss the potential sources of antibiotics in coastal waters. The detailed information on PMF refers to guideline of USEPA (2014).

\subsection{Ecological risk assessment}

Ecological risks of antibiotics in aquatic environments are generally evaluated using risk quotients ( $R Q s)$. Targeting at aquatic organisms, $R Q s$ are calculated according to the following equation (Biel-Maeso et al., 2018; Chen et al., 2015b; Zhang et al., 2013):

$R Q=\frac{M E C}{P N E C}$

where $M E C$ and $P N E C$ are the measured environmental concentrations and the predicted no-effect concentrations, respectively.

European Commission (EC, 2003) has released technical guidance document on risk assessment and provided calculation of PNEC as follows:

$P N E C=\frac{\text { Endpo } \text { int }_{\text {Toxicity }}}{A F}$

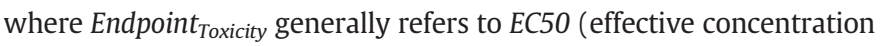
for $50 \%$ of test organisms) standing for acute toxicity and NOEC (no observable effect concentration) representing chronic toxicity of the target chemical for non-target organisms; $A F$ is assessment factor.

Based on guideline of EC (2003), values of $A F$ are determined as 1000 for $E C 50 . A F$ values can be set as 100, 50, and 10 when $N O E C(\mathrm{~s})$ from the species representing one, two, or at least three trophic levels (EC, 2003). Therefore, this study firstly screened toxicity data of the detected antibiotics through ECOTOX database (https://cfpub.epa.gov/ecotox/), and then verified toxicity data with the corresponding references (Ando et al., 2007; Brain et al., 2004; Brain et al., 2008; Carballeira et al., 2012; De Orte et al., 2013; Ferrari et al., 2004; Isidori et al., 2005; Kim et al., 2010; Láng and Kőhidai, 2012; Laville et al., 2004; Li et al., 2012; Liu et al., 2014; Lu et al., 2013; Melvin et al., 2014; Richards and Cole,
2006; Wollenberger et al., 2000; Yang et al., 2008; Yu et al., 2011). The lowest EC50 or NOEC was taken to represent the toxicity endpoint for each class of non-target organisms based on "the worst case" scenario (Table S1). Both EC50 and NOEC were chosen to obtain $P N E C_{A}$ at acute toxicity scenario and $P N E C_{C}$ at chronic toxicity scenario, respectively (Table S2). Thus $R Q_{A}$ and $R Q_{C}$ were calculated using $P N E C_{A}$ and $P N E C_{C}$ for short-term and long-term ecological risks, respectively.

Ecological risks are determined as insignificant risk with $\mathrm{RQ}<0.01$, low risk with $0.01<\mathrm{RQ} \leq 0.1$, moderate risk with $0.1<\mathrm{RQ} \leq 1$, and high risk with RQ > 1 (Biel-Maeso et al., 2018; Chen et al., 2015b; Hernando et al., 2006).

\subsection{Health risk assessment}

Dermal contact including surfing, swimming, and diving is the main exposure path of antibiotics in coastal waters. Boursi et al. (2015) reported that cancer risk in some specific organ sites might be associated with recurrent exposure to some antibiotics. Therefore, this study used cancer and non-cancer risks to evaluate the potential health risks of antibiotics. Cancer risk $(C R)$ and hazard quotient $(H Q)$ of individual pollutant through dermal contact were calculated using the following equations (Akhbarizadeh et al., 2016; Sarria-Villa et al., 2016; USEPA, 2004):

$$
\begin{aligned}
& C R(\text { individual })=D A D \times \frac{S F}{G I A B S}=D A_{\text {event }} \times \frac{E V \times E D \times E F \times S A}{B W \times A T} \times \frac{S F}{G I A B S} \\
& =2 \times F A \times K_{P} \times C_{W} \times \sqrt{\frac{6 \times \tau_{\text {event }} \times t_{\text {event }}}{\pi}} \times \frac{E V \times E D \times E F \times S A}{B W \times A T} \times \frac{S F}{G I A B S} \\
& H Q(\text { individual })=D A D \times \frac{1}{R f D \times G I A B S}=D A_{\text {event }} \times \frac{E V \times E D \times E F \times S A}{B W \times A T} \times \frac{1}{R f D \times G I A B S} \\
& =2 \times F A \times K_{P} \times C_{W} \times \sqrt{\frac{6 \times \tau_{\text {event }} \times t_{\text {event }}}{\pi}} \times \frac{E V \times E D \times E F \times S A}{B W \times A T} \times \frac{1}{R f D \times G I A B S}
\end{aligned}
$$

$C R=\sum C R($ individual $)$

$H Q=\sum H Q($ individual $)$

where $D A_{\text {event }}$ and $D A D$ are absorbed dose per event and dermal absorbed dose, respectively; $E D, E F$, and $E V$ refer to exposure duration, exposure frequency, and the event frequency, respectively; $S A$ is skin surface area; $B W$ stands for body weight; $A T$ refers to average lifespan; $S F$ represents oral slope factor; RfD represents oral reference dose; GIABS is the fraction of pollutant absorbed in gastrointestinal tract; $F A$ is the fraction of absorbed water; $\tau_{\text {event }}$ refers to lag time per event; $t_{\text {event }}$ is event duration; $K_{\mathrm{P}}$ is dermal permeability coefficient of pollutant; $C_{W}$ 
represents concentration of target antibiotics in coastal water. The values of parameters were cited from the references (Akhbarizadeh et al., 2016; Man et al., 2013; Sarria-Villa et al., 2016; USEPA, 2004; USEPA, 2016) and listed in Table S3.

It is hard to obtain values of $K_{\mathrm{p}}$ directly from the references. So a model developed by ten Berge (2010), also recommended by Brown et al. (2016) after they performed comparison study on existing 8 models aiming at calculating $K_{p}$, was used in this study to calculate $K_{p}$ values of target antibiotics.

$K_{p}=\frac{1}{\frac{1}{K_{\text {lip }}+K_{\text {pol }}}+\frac{1}{K_{a q}}}$

$\log K_{\text {lip }}=-2.69+0.981 \log K_{\text {ow }}-0.0079 M W$

$K_{\text {pol }}=\frac{0.0552}{M W^{1.38}}$

$K_{a q}=\frac{1121}{M W^{1.96}}$

where $K_{\text {lip }}$ refers to permeation coefficient of the lipid medium; $K_{\text {pol }}$ is permeation coefficient of protein fraction of stratum corneum; $K_{a q}$ is permeation coefficient of watery dermal layer; $K_{o w}$ is octanol-water partition coefficient; $M W$ is molecular weight of the target compound.

It is difficult to obtain $S F$ values of target antibiotics. Therefore, a model developed by Zeise et al. (1984) was adopted to estimate $S F$ values. Zeise et al. (1984) used $\beta_{a}$ and $\beta_{h}$ to represent the measured potency in an animal experiment and estimated carcinogenic potency for humans. We assumed that $\beta_{a}=S F$ for target antibiotics in this study.

$\beta_{h}=\beta_{a} \times K_{a h}$

$\log \beta_{a}=C \times \log L D 50+\log D$

where $K_{a h}$ is an interspecies extrapolation factor and set as 4.7 based on Crouch and Wilson (1979); $C$ and $D$ are parameters targeting at different experimental animals and reported by Zeise et al. (1984); LD50 is acute median lethal dose of target compound. LD50 of each compound was obtained from U.S. National Library of Medicine Database (https://toxnet.nlm.nih.gov/) and listed in Table S4.

RfD was estimated according to Strenge and Peterson (1989):

$R f D=L D 50 \times 4 \times 10^{-5}$

The calculated $K_{p}, S F$, and $R f D$ of target antibiotics were listed in Table S4.

\section{Results and discussion}

\subsection{Distribution of target antibiotics in coastal waters}

Only 7 target antibiotics including SDZ, SMX, SMM, SM, NFC, CFC, and RTM were detected in coastal water samples (Fig. 1). The detection frequencies of sulfonamides ranged from 2.94\% (SDZ) to $11.76 \%$ (SMX and SMM). SMX was mainly detected in the coastal water samples from the estuaries and the maricultural zone while SDZ was only detected in water sample from the maricultural zone. SM and SMM existed in coastal waters of the bathing beach and the maricultural zone and SMM also existed in estuarine water. In contrast, NFC, RTM, and CFC were the most frequently detected in coastal waters from the maricultural zones, bathing beaches, estuaries, and ports, with detection frequencies of $100 \%, 100 \%$, and $94.12 \%$, respectively. Total concentrations of target antibiotics were in the range of 389-3302.3 ng/L with the average value of $773.99 \mathrm{ng} / \mathrm{L}$ (Fig. 1). Quinolones averagely contributed to $83.85 \%$ of total antibiotics. NFC served as the dominant antibiotic, and followed by CFC and RTM. The concentrations of NFC, CFC, and RTM in coastal waters were in the ranges of 280-1990, 243-1230, and $80.5-109 \mathrm{ng} / \mathrm{L}$, respectively. The dominant antibiotics in coastal waters of this study were different from the previous studies (Chen et al., 2015b, 2017; Zhang et al., 2013). The concentrations of NFC in coastal waters along coastline of China were much higher than those in seawater of the Persian Gulf, Iran (Kafaei et al., 2018). The concentrations of detected SMX in coastal waters of this study were higher than those in a Mediterranean coastal lagoon (Moreno-González et al., 2015). The concentrations of fluoroquinolones and sulfonamides in coastal waters were much higher than those from coastal area of Korea (Kim et al., 2017). The total concentrations of antibiotics were generally higher than those reported by Chen et al. (2017) and Zhang et al. (2013). Interestingly, the maximal total concentration of antibiotics in coastal waters of this study was much lower than that reported by Chen et al. (2015b). These results illustrated that sampling sites and surrounding environments might have important impact on the occurrence and distribution of antibiotics in coastal waters. Accordingly, frequent detection of these veterinary or human medicines in coastal waters might account for the possible impact on the aquatic ecosystems including the fish farms. Concentrations of antibiotics in aquaculture tail water samples significantly higher than those in other coastal water samples (Fig. 1), indicating that aquaculture tail water might be an important source of antibiotics for coastal waters.

\subsection{Source apportionment of antibiotics in coastal waters}

The potential relationship between antibiotics and water quality parameters was illustrated by Pearson correlation coefficients (Table 1) while the distribution of salinity, TOC, TN, and TP in coastal waters was shown in Fig. S1. Salinity of water samples ranged from $2 \%$ to $35 \%$. Concentrations of TOC, TN, and TP were in the ranges of

Table 1

Pearson correlation analysis on concentrations of antibiotics and water quality parameters.

\begin{tabular}{|c|c|c|c|c|c|c|c|c|c|c|c|}
\hline & SDZ & SMX & SMM & SM & NFC & CFC & RTM & Salinity & TOC & $\mathrm{TN}$ & $\mathrm{TP}$ \\
\hline SDZ & 1.000 & & & & & & & & & & \\
\hline SMX & $0.466^{* *}$ & 1.000 & & & & & & & & & \\
\hline SMM & 0.238 & 0.153 & 1.000 & & & & & & & & \\
\hline SM & -0.036 & -0.067 & $0.867^{* *}$ & 1.000 & & & & & & & \\
\hline NFC & -0.052 & -0.075 & -0.063 & -0.028 & 1.000 & & & & & & \\
\hline $\mathrm{CFC}$ & -0.015 & -0.025 & -0.028 & -0.020 & $0.902^{* *}$ & 1.000 & & & & & \\
\hline RTM & 0.009 & 0.251 & -0.042 & 0.001 & -0.152 & -0.171 & 1.000 & & & & \\
\hline Salinity & $-0.354^{*}$ & $-0.382^{*}$ & -0.285 & -0.006 & 0.173 & 0.115 & 0.169 & 1.000 & & & \\
\hline TOC & -0.040 & 0.168 & 0.221 & 0.022 & 0.051 & 0.083 & -0.085 & $-0.671^{* *}$ & 1.000 & & \\
\hline TN & -0.183 & 0.252 & -0.138 & -0.071 & 0.040 & -0.108 & 0.160 & 0.003 & -0.046 & 1.000 & \\
\hline TP & -0.011 & 0.015 & -0.080 & -0.040 & 0.205 & -0.078 & 0.098 & 0.032 & 0.038 & $0.553^{* *}$ & 1.000 \\
\hline
\end{tabular}

** Means the significant level at $\mathrm{p}<0.01$

* Means the significant level at $\mathrm{p}<0.05$. 


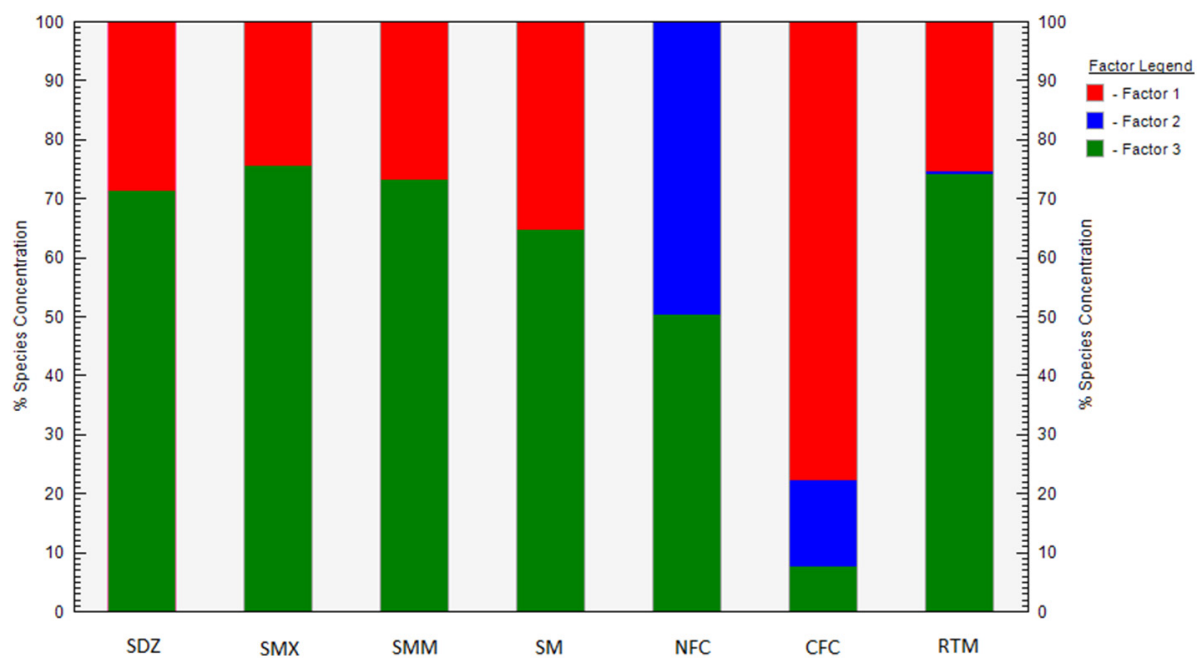

Fig. 2. Factor fingerprints of detected antibiotics in coastal waters.

2.47-29.42, 0.56-3.88, and 0.01-0.65 mg/L, respectively. According to the Pearson correlation coefficients, significant positive correlation existed between SDZ \& SMX, SMM \& SM, and NFC \& CFC at significant level $\mathrm{p}<0.01$. This showed that close relationship more easily existed between the antibiotics with similar structure. SDZ and SMX were negatively related with salinity at significant level $p<0.05$, similar with several pharmaceutically active compounds reported by Biel-Maeso et al. (2018). It is interesting that antibiotics did not relate with TOC, TN, and TP, suggesting that more complex factors might affect the relationship among these indices.

Three factors (potential sources) of antibiotics in coastal waters along Chinese coastline were determined by PMF model (Fig. 2). Sulfonamides and macrolides (RTM) mainly derived from veterinary-drug sources (factor 3 ) such as aquaculture because sulfonamides and macrolides are mainly used in animal breeding (Zhang et al., 2015). CFC of this study mainly came from anthropogenic sources (factor
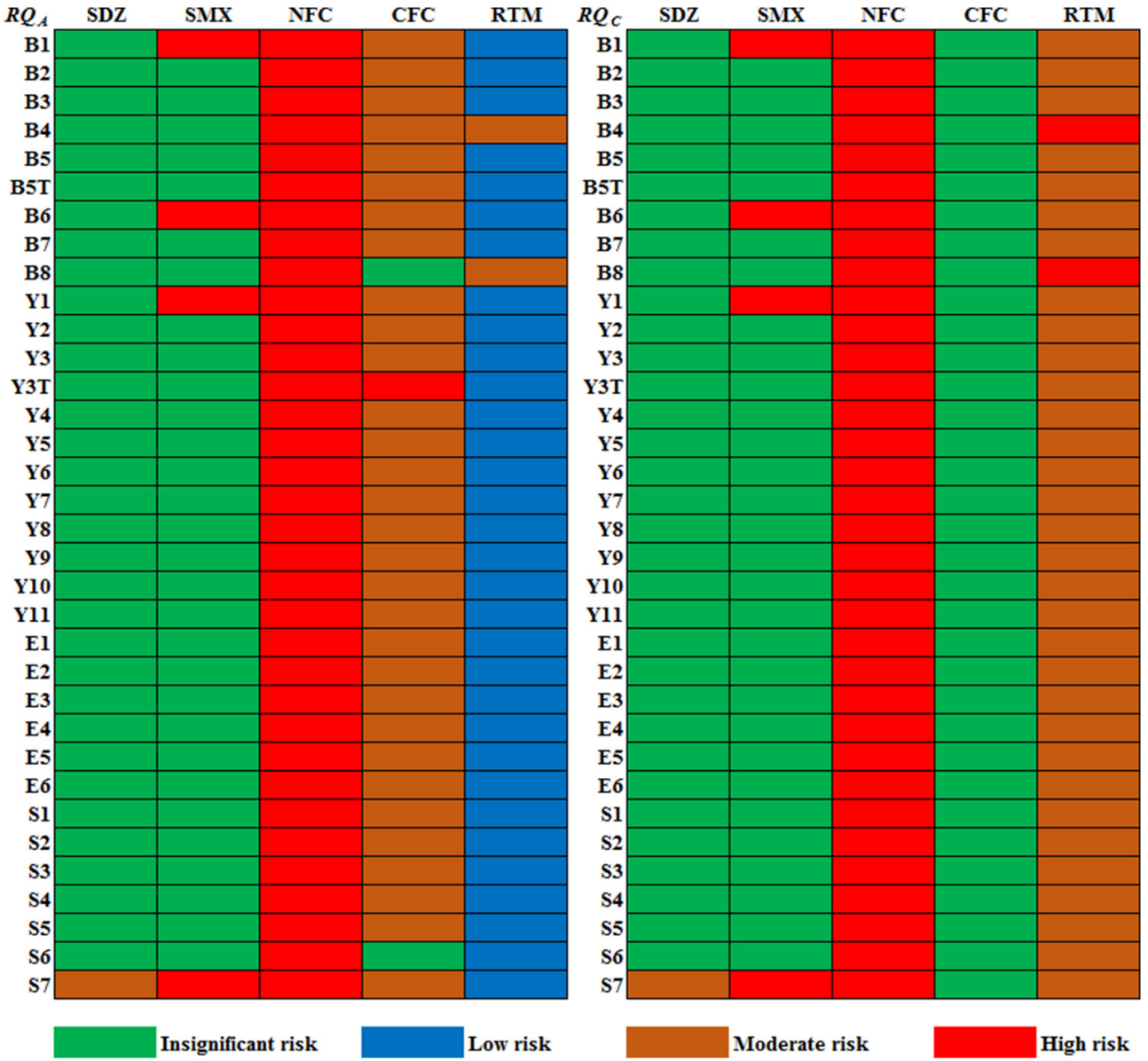

Fig. 3. Ecological risks of antibiotics in coastal waters. $R Q_{A}$ and $R Q_{C}$ are risk quotient based on acute toxicity and chronic toxicity, respectively. 
1) such as domestic sewage since it has been forbidden for aquaculture in China. NFC mainly originated from two sources including veterinarydrug sources (factor 3 ) and mixed sources (factor 2). Mixed sources might possess complex compositions such as riverine inputs, runoff, direct tail water discharge, and so on. Identification on sources of antibiotics in coastal waters will provide useful basis for controlling pollution and potential risks exerted by antibiotics.

\subsection{Ecological risks of antibiotics in coastal waters}

Toxicity data of SMM and SM were not available from ECOTOX database so that ecological risks of these antibiotics were not calculated. In contrast to other research work (Chen et al., 2015b, 2017; Zhang et al., 2013), this study further divided the ecological risks posed by the antibiotics into short-term and long-term risks to comprehensively illustrate the potential impacts of the antibiotics in coastal waters. $R Q_{A}$ of the remaining antibiotics varied from 0 (SDZ, SMX, and CFC) to 63.69 (SMX) while $R Q_{C}$ ranged from 0 (SDZ, SMX, and CFC) to 12.44 (NFC). Based on evaluation criterion, ecological risk levels of these antibiotics were clearly shown in Fig. 3. SMX and NFC were the important contributors of ecological risks due to their low PNEC values. Both short-term and long-term ecological risks posed by detected NFC and SMX were at high levels and also higher than risks previously reported (Chen et al., 2017; Zhang et al., 2013), suggesting that it is necessary to effectively control NFC and SMX in coastal waters. Interestingly, CFC posed moderate short-term risks for aquatic organisms while it exerted insignificant risks in the long term due to relatively high PNECC value. Longterm risks of CFC in coastal waters were lower than those reported by Chen et al. (2015b). These results might enlighten us that relatively low concentrations of CFC will not cause significant ecological risks for aquatic organisms in the long term. In contrast, RTM posed low risks in the short term while it exerted moderate risks in the long term, suggesting that RTM might cause long lasting consequences for aquatic ecosystems. SDZ was detected at one site (S7) with moderate ecological risks which were higher than those reported by Zhang et al. (2013). Therefore, SDZ still needed attention and effective control. Considering that some antibiotics are reported to bio-accumulate in the non-target marine organism (Chen et al., 2015a; Bris and Pouliquen, 2004; Liu et al., 2018), ecological risks posed by antibiotics in coastal waters deserve more attention.

Risk quotient approach is somewhat limited for marine and coastal environments due to the scarce toxicity data on marine aquatic species for emerging contaminants. In Table S1, only Phaeodactylum tricornutum, Arbacia lixula, Synechococcus leopoliensis are marine species while Daphnia magna, Microcystis aeruginosa, and Pseudokirchneriella subcapitata are brackish tolerant species. However, the toxicity data on freshwater species are still employed in this study because of considering that coastal water environments are complex aquatic systems and more toxicity data will make the risk assessment results more comprehensive and credible.

\subsection{Health risks of antibiotics in coastal waters}

Although antibiotics have been reported to pose potential health risks to human beings (Liu et al., 2017; Wang et al., 2017), information on the health risks of antibiotics in coastal water is still very limited. Therefore, this study employed model to evaluate the health risks of target antibiotics in coastal waters through dermal contact. Cancer risks of

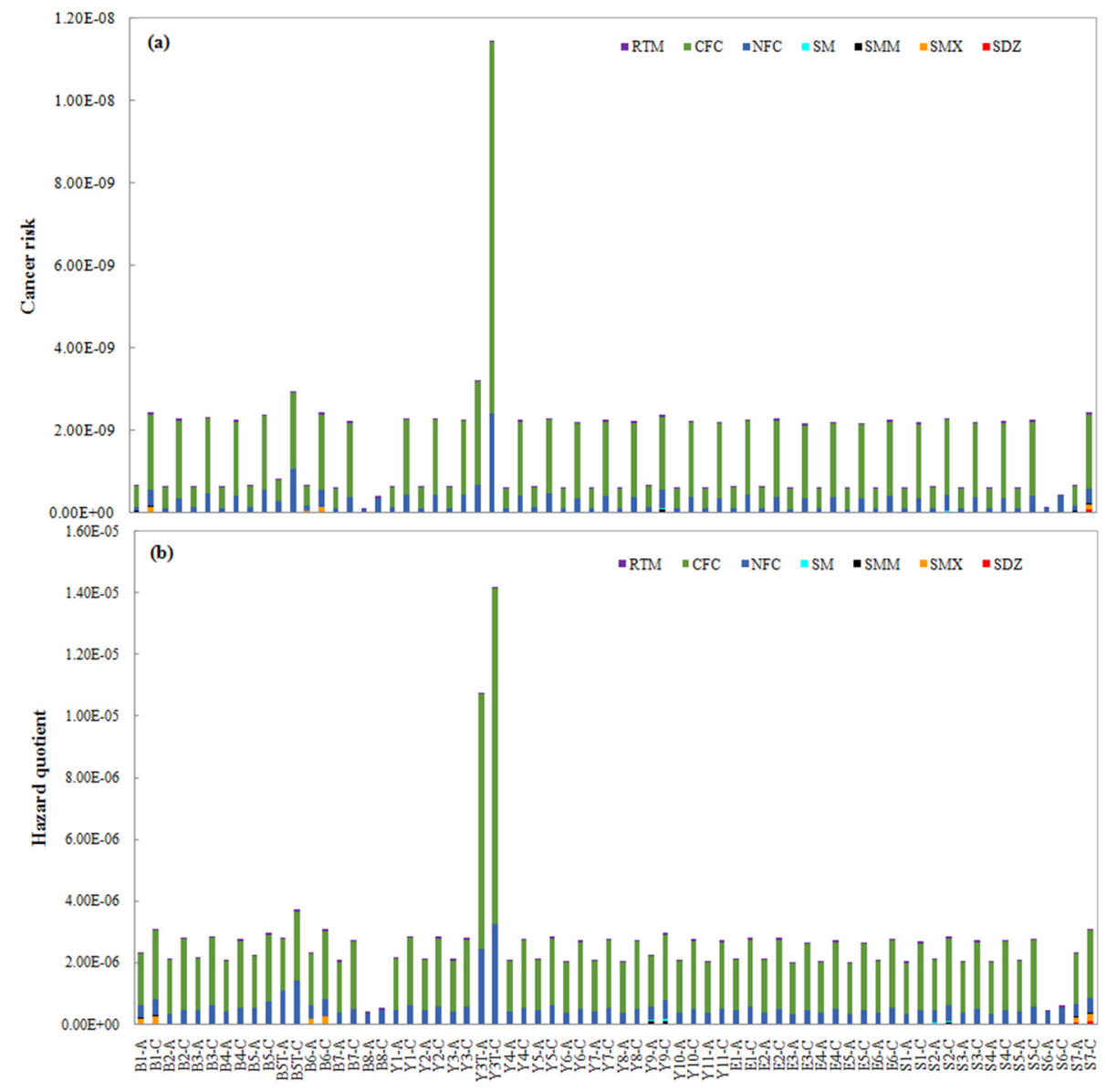

Fig. 4. Health risks of antibiotics in coastal waters. A and C refer to adults and children, respectively. 
antibiotics varied from $1.14 \times 10^{-10}$ to $3.23 \times 10^{-9}$ for adults and from $4.04 \times 10^{-10}$ to $1.15 \times 10^{-8}$ for children (Fig. 4a). The average cancer risks for adults and children were $6.92 \times 10^{-10}$ to $2.46 \times 10^{-9}$, respectively. Based on ranking criterion (Ge et al., 2013), antibiotics in coastal waters at all sampling sites posed very low cancer risks for both adults and children. Cancer risks for children were approximately 3.6 times of those for adults. CFC was the dominant donor for cancer risks with average contribution proportion of $74.08 \%$. NFC served as the second contributor for cancer risks with average contribution proportion of $22.48 \%$. In terms of B8 and S6 at which CFC was not detected, NFC contributed to $86.27 \%$ and $90.26 \%$ of cancer risks, respectively. RTM contributed to $0.39 \%-13.73 \%$ of cancer risks at all sites.

Non-cancer risks of antibiotics in coastal waters ranged from 4.09 $\times 10^{-7}$ to $1.08 \times 10^{-5}$ for adults and from $5.40 \times 10^{-7}$ to $1.42 \times 10^{-5}$ for children (Fig. $4 \mathrm{~b}$ ). The average non-cancer risks for adults and children were $2.31 \times 10^{-6}$ and $3.05 \times 10^{-6}$, respectively. Non-cancer risks of antibiotics for both adults and children were at negligible level because all HQs were below threshold of 1.0. Non-cancer risks for children were approximately 1.3 times of those for adults. Similar to cancer risks, CFC served as the dominant contributor for non-cancer risks while NFC contributed to over $86 \%$ of non-cancer risks at B8 and S6. RTM averagely contributed to $2.56 \%$ of non-cancer risks at all sites. Noncancer risks posed by antibiotics might be negligible due to very low HQs.

\section{Conclusions}

The pollution, the short-term and long-term ecological risks, and health risks of antibiotics in the coastal waters along nearly $18,000 \mathrm{~km}$ of Chinese coastline were investigated. Seven out of thirteen antibiotics were detected in coastal waters. Total concentrations of target antibiotics were in the range of 389-3302.3 ng/L. NFC, RTM, and CFC were detected in coastal waters at over $94 \%$ of sampling sites, associated with the maximal concentrations of 1990,1230, and $109 \mathrm{ng} / \mathrm{L}$. Antibiotics, except SDZ and SMX that were negatively related with salinity at significant level $\mathrm{p}<0.05$, did not relate with water quality parameters including salinity, TOC, TN, and TP. Three factors (potential sources) including veterinary-drug sources, anthropogenic sources, and mixed sources affected the distribution of antibiotics in coastal waters. Both short-term and long-term ecological risks posed by detected NFC and SMX were at high levels. CFC posed moderate short-term ecological risks but insignificant long-term risks for aquatic organisms. RTM posed low ecological risks in the short term while it exerted moderate risks in the long term. Antibiotics exerted very low cancer risks for both adults and children at all sampling sites. Accordingly, non-cancer risks of antibiotics for both adults and children were at negligible levels. Antibiotics in coastal water still need effective control due to potential ecological-health risks they pose.

\section{Acknowledgements}

This work was financially supported by National Natural Science Foundation of China (No. 41671319), One Hundred Talents Program of Chinese Academy of Sciences (Grant numbers of Y629041021 and Y610061033), Key Research Program of Frontier Sciences of CAS (Grant No. QYZDJ-SSW-DQC015), and Two-Hundred Talents Plan of Yantai (Y739011021). The authors would like to thank the reviewers for their valuable suggestions and comments on the manuscript.

\section{Appendix A. Supplementary data}

Supplementary data to this article can be found online at https://doi. org/10.1016/j.scitotenv.2018.07.096.

\section{References}

Akhbarizadeh, R., Moore, F., Keshavarzi, B., Moeinpour, A., 2016. Aliphatic and polycyclic aromatic hydrocarbons risk assessment in coastal water and sediments of Khark Island, SW Iran. Mar. Pollut. Bull. 108, 33-45.

Ando, T., Nagase, H., Eguchi, K., Hirooka, T., Nakamura, T., Miyamoto, K., Hirata, K., 2007. A novel method using cyanobacteria for ecotoxicity test of veterinary antimicrobial agents. Environ. Toxicol. Chem. 26 (4), 601-606.

Biel-Maeso, M., Baena-Nogueras, R.M., Corada-Fernández, C., Lara-Martín, P.A., 2018. Occurrence, distribution and environmental risk of pharmaceutically active compounds (PhACs) in coastal and ocean waters from the Gulf of Cadiz (SW Spain). Sci. Total Environ. 612, 649-659.

Boursi, B., Mamtani, R., Haynes, K., Yang, Y.-X., 2015. Recurrent antibiotic exposure may promote cancer formation - another step in understanding the role of the human microbiota? Eur. J. Cancer 51, 2655-2664.

Brain, R.A., Johnson, D.J., Richards, S.M., Sanderson, H., Sibley, P.K., Solomon, K.R., 2004. Effects of 25 pharmaceutical compounds to Lemna gibba using a seven-day staticrenewal test. Environ. Toxicol. Chem. 23 (2), 371-382.

Brain, R.A., Ramirez, A.J., Fulton, B.A., Chambliss, C.K., Brooks, B.W., 2008. Herbicidal effects of sulfamethoxazole in Lemna gibba: using p-aminobenzoic acid as a biomarker of effect. Environ. Sci. Technol. 42 (23), 8965-8970.

Bris, H.L., Pouliquen, H., 2004. Experimental study on the bioaccumulation of oxytetracycline and oxolinic acid by the blue mussel (Mytilus edulis). An evaluation of its ability to bio-monitor antibiotics in the marine environment. Mar. Pollut. Bull. 48, 434-440.

Brown, T.N., Armitage, J.M., Egeghy, P., Kircanski, I., Arnot, J.A., 2016. Dermal permeation data and models for the prioritization and screening-level exposure assessment of organic chemicals. Environ. Int. 94, 424-435.

Carballeira, C., De Orte, M.R., Viana, I.G., DelValls, T.A., Carballeira, A., 2012. Assessing the toxicity of chemical compounds associated with land-based marine fish farms: the sea urchin embryo bioassay with Paracentrotus lividus and Arbacia lixula. Arch. Environ. Contam. Toxicol. 63 (2), 249-261.

Carvalho, I.T., Santos, L., 2016. Antibiotics in the aquatic environments: a review of the European scenario. Environ. Int. 94, 736-757.

Chen, H., Liu, S., Xu, X.-R., Liu, S.-S., Zhou, G.-J., Sun, K.-F., Zhao, J.-L., Ying, G.-G., 2015a. Antibiotics in typical marine aquaculture farms surrounding Hailing Island, South China: occurrence, bioaccumulation and human dietary exposure. Mar. Pollut. Bull. 90, 181-187.

Chen, H., Liu, S., Xu, X.-R., Zhou, G.-I., Liu, S.-S., Yue, W.-Z., Sun, K.-F., Ying, G.-G., 2015b. Antibiotics in the coastal environment of the Hailing Bay region, South China Sea: spatial distribution, source analysis and ecological risks. Mar. Pollut. Bull. 95, 365-373.

Chen, C.Q., Zheng, L., Zhou, J.L., Zhao, H., 2017. Persistence and risk of antibiotic residues and antibiotic resistance genes in major mariculture sites in Southeast China. Sci. Total Environ. 580, 1175-1184.

Crouch, E., Wilson, R., 1979. Interspecies comparison of carcinogenic potency. J. Toxicol. Environ. Health B 5, 1095-1118.

De Orte, M.R., Carballeira, C., Viana, I.G., Carballeira, A., 2013. Assessing the toxicity of chemical compounds associated with marine land-based fish farms: the use of mini-scale microalgal toxicity tests. Chem. Ecol. 29 (6), 554-563.

European Commission, 2003. Technical Guidance Document on Risk Assessment in Support of Commission Directive 93/67/EEC on Risk Assessment for New Notified Substances/Commission Regulation (EC) No 1488/94 on Risk Assessment for Existing Substances/Directive 98/8/EC of the European Parliament and of the Council Concerning the Placing of Biocidal Products on the Market (Printed in Italy).

Ferrari, B., Mons, R., Vollat, B., Fraysse, B., Paxéus, N., Lo Giudice, R., Pollio, A., Garric, J., 2004. Environmental risk assessment of six human pharmaceuticals: are the current environmental risk assessment procedures sufficient for the protection of the aquatic environment? Environ. Toxicol. Chem. 23, 1344-1354.

Ge, J., Woodward, L.A., Li, Q.X., Wang, J., 2013. Composition, distribution and risk assessment of organochlorine pesticides in soils from the Midway Atoll, North Pacific Ocean. Sci. Total Environ. 452-453, 421-426.

Gross, M., 2013. Antibiotics in crisis. Curr. Biol. 23:R1063-R1065. https://doi.org/10.1016/ j.cub.2013.11.057.

He, X., Deng, M., Wang, Q., Yang, Y., Yang, Y., Nie, X., 2016. Residues and health risk assessment of quinolones and sulfonamides in cultured fish from Pearl River Delta, China. Aquaculture 458, 38-46.

Hernando, M.D., Mezcua, M., Fernandez-Alba, A.R., Barcelo, D., 2006. Environmental risk assessment of pharmaceutical residues in wastewater effluents, surface waters and sediments. Talanta 69, 334-342.

Huang, Y., Cheng, M., Li, W., Wu, L., Chen, Y., Luo, Y., Christie, P., Zhang, H., 2013. Simultaneous extraction of four classes of antibiotics in soil, manure and sewage sludge and analysis by liquid chromatography-tandem mass spectrometry with the isotopelabelled internal standard method. Anal. Methods 5, 3721-3731.

Hvistendahl, M., 2012. China takes aim at rampant antibiotic resistance. Science 336, 795.

Isidori, M., Lavorgna, M., Nardelli, A., Pascarella, L., Parrella, A., 2005. Toxic and genotoxic evaluation of six antibiotics on non-target organisms. Sci. Total Environ. 346 (1-3), 87-98.

Kafaei, R., Papari, F., Seyedabadi, M., Sahebi, S., Tahmasebi, R., Ahmadi, M., Sorial, G.A., Asgari, G., Ramavandi, B., 2018. Occurrence, distribution, and potential sources of antibiotics pollution in the water-sediment of the northern coastline of the Persian Gulf, Iran. Sci. Total Environ. 627, 703-712.

Kim, J., Park, J., Kim, P.-G., Lee, C., Choi, K., Choi, K., 2010. Implication of global environmental changes on chemical toxicity-effect of water temperature, $\mathrm{pH}$, and ultraviolet B irradiation on acute toxicity of several pharmaceuticals in Daphnia magna. Ecotoxicology 19 (4), 662-669.

Kim, H.-Y., Lee, I.-S., Oh, J.-E., 2017. Human and veterinary pharmaceuticals in the marine environment including fish farms in Korea. Sci. Total Environ. 579, 940-949. 
Láng, J., Kőhidai, L., 2012. Effects of the aquatic contaminant human pharmaceuticals and their mixtures on the proliferation and migratory responses of the bioindicator freshwater ciliate Tetrahymena. Chemosphere 89 (5), 592-601.

Laville, N., Ait-Aissa, S., Gomez, E., Casellas, C., Porcher, J.M., 2004. Effects of human pharmaceuticals on cytotoxicity, EROD activity and ROS production in fish hepatocytes. Toxicology 196, 41-55.

Li, Z., Lu, G., Yang, X., Wang, C., 2012. Single and combined effects of selected pharmaceuticals at sublethal concentrations on multiple biomarkers in Carassius auratus. Ecotoxicology 21 (2), 353-361.

Li, N., Ho, K.W.K., Ying, G.-G., Deng, W.-J., 2017. Veterinary antibiotics in food, drinking water, and the urine of preschool children in Hong Kong. Environ. Int. 108, 246-252.

Liu, J., Lu, G., Wu, D., Yan, Z., 2014. A multi-biomarker assessment of single and combined effects of norfloxacin and sulfamethoxazole on male goldfish (Carassius auratus). Ecotoxicol. Environ. Saf. 102, 12-17.

Liu, S., Zhao, G., Zhao, H., Zhai, G., Chen, J., Zhao, H., 2017. Antibiotics in a general population: relations with gender, body mass index (BMI) and age and their human health risks. Sci. Total Environ. 599-600, 298-304

Liu, S., Bekele, T.-G., Zhao, H., Cai, X., Chen, J., 2018. Bioaccumulation and tissue distribution of antibiotics in wild marine fish from Laizhou Bay, North China. Sci. Total Environ. 631-632, 1398-1405.

Lu, G., Li, Z., Liu, J., 2013. Effects of selected pharmaceuticals on growth, reproduction and feeding of Daphnia magna. Fresenius Environ. Bull. 22 (9), 2583-2589.

Man, Y.B., Kang, Y., Wang, H.S., Lau, W., Li, H., Sun, X.L., Giesy, J.P., Chow, K.L., Wong, M.H., 2013. Cancer risk assessments of Hong Kong soils contaminated by polycyclic aromatic hydrocarbons. J. Hazard. Mater. 261, 770-776.

Melvin, S.D., Cameron, M.C., Lanctot, C.M., 2014. Individual and mixture toxicity of pharmaceuticals naproxen, carbamazepine, and sulfamethoxazole to Australian striped marsh frog tadpoles (Limnodynastes peronii). J. Toxicol. Environ. Health A 77 (6), 337-345.

Meng, W., Hu, B., He, M., Liu, B., Mo, X., Li, H., Wang, Z., Zhang, Y., 2017. Temporal-spatial variations and driving factors analysis of coastal reclamation in China. Estuar. Coast. Shelf Sci. 191, 39-49.

Minh, T.B., Leung, H.W., Loi, I.H., Chan, W.H., So, M.K., Mao, J.Q., Choi, D., Lam, J.C.W. Zheng, G., Martin, M., Lee, J.H.W., Lam, P.K.S., Richardson, B.J., 2009. Antibiotics in the Hong Kong metropolitan area: ubiquitous distribution and fate in Victoria Harbour. Mar. Pollut. Bull. 58, 1052-1062.

Moreno-González, R., Rodriguez-Mozaz, S., Gros, M., Barceló, D., León, V.M., 2015. Seasonal distribution of pharmaceuticals in marine water and sediment from a mediterranean coastal lagoon (SE Spain). Environ. Res. 138, 326-344.

ten Berge, W., 2010. QSARs for skin permeation of chemicals. URL:. http://home.wxs.nl/ wtberge/qsarperm.Html, Accessed date: 14 March 2018.

Nödler, K., Voutsa, D., Licha, T., 2014. Polar organic micropollutants in the coastal environment of different marine systems. Mar. Pollut. Bull. 85, 50-59.

Qiao, M., Ying, G.-G., Singer, A.C., Zhu, Y.-G., 2018. Review of antibiotic resistance in China and its environment. Environ. Int. 110, 160-172.

Richards, S.M., Cole, S.E., 2006. A toxicity and hazard assessment of fourteen pharmaceuticals to Xenopus laevis larvae. Ecotoxicology 15 (8), 647-656.

Sarria-Villa, R., Ocampo-Duque, W., Páez, M., Schuhmacher, M., 2016. Presence of PAHs in water and sediments of the Colombian Cauca River during heavy rain episodes, and implications for risk assessment. Sci. Total Environ. 540, 455-465.

Strenge, D.L., Peterson, S.R., 1989. Chemical Data Bases for the Multimedia Environmental Pollutant Assessment System (MEPAS). Pacific Northwest Lab., Richland, WA, USA: p. 70 https://doi.org/10.2172/6610163 (Web).
Sun, J., Zeng, Q., Tsang, D.C.W., Zhu, L.Z., Li, X.D., 2017. Antibiotics in the agricultural soils from the Yangtze River Delta, China. Chemosphere 189, 301-308.

USEPA (U.S. Environmental Protection Agency), 2004. Risk Assessment Guidance for Superfund Volume I: Human Health Evaluation Manual (Part E, Supplemental Guidance for Dermal Risk Assessment). Office of Superfund Remediation and Technology Innovation, Washington, DC.

USEPA (U.S. Environmental Protection Agency), 2014. EPA Positive Matrix Factorization (PMF) 5.0 Fundamentals and User Guide. EPA/600/R-14/108.

USEPA (U.S. Environmental Protection Agency), 2016. Regional Screening Levels (RSLs) user's guide. Available on. https://www.epa.gov/risk/regional-screening-levels-rslsusers-guide-may-2016.

Wang, H., Wang, N., Qian, J., Hu, L., Huang, P., Su, M., Yu, X., Fu, C., Jiang, F., Zhao, Q., Zhou, Y., Lin, H., He, G., Chen, Y., Jiang, Q., 2017. Urinary antibiotics of pregnant women in Eastern China and cumulative health risk assessment. Environ. Sci. Technol. 51 3518-3525.

Wang, J.-H., Lu, J., Zhang, Y.-X., Wu, J., Luo, Y., Liu, H., 2018. Metagenomic analysis of antibiotic resistance genes in coastal industrial mariculture systems. Bioresour. Technol. 253, 235-243.

Wen, X., Feng, Q., Lu, J., Wu, J., Wu, M., Guo, X., 2018. Risk assessment and source identification of coastal groundwater nitrate in northern China using dual nitrate isotopes combined with Bayesian mixing model. Hum. Ecol. Risk. Assess. 24, 1043-1057.

Wollenberger, L., Halling-Sorensen, B., Kusk, K.O., 2000. Acute and chronic toxicity of veterinary antibiotics to Daphnia magna. Chemosphere 40 (7), 723-730.

Yang, L.-H., Ying, G.-G., Su, H.-C., Stauber, J.L., Adams, M.S., Binet, M.T., 2008. Growthinhibiting effects of 12 antibacterial agents and their mixtures on the freshwater microalga Pseudokirchneriella subcapitata. Environ. Toxicol. Chem. 27 (5) 1201-1208.

Yu, Z., Jiang, L., Yin, D., 2011. Behavior toxicity to Caenorhabditis elegans transferred to the progeny after exposure to sulfamethoxazole at environmentally relevant concentrations. J. Environ. Sci. 23 (2), 294-300.

Zeise, L., Wilson, R., Crouch, E., 1984. Use of acute toxicity to estimate carcinogenic risk Risk Anal. 4 (3), 187-199.

Zhang, R., Tang, J., Li, J., Cheng, Z., Chaemfa, C., Liu, D., Zheng, Q., Song, M., Luo, C., Zhang, G. 2013. Occurrence and risks of antibiotics in the coastal aquatic environment of the Yellow Sea, North China. Sci. Total Environ. 450-451, 197-204.

Zhang, Q.-Q., Ying, G.-G., Pan, C.-G., Liu, Y.-S., Zhao, J.-L., 2015. Comprehensive evaluation of antibiotics emission and fate in the river basins of China: source analysis, multimedia modeling, and linkage to bacterial resistance. Environ. Sci. Technol. 49, 6772-6782.

Zheng, Q., Zhang, R., Wang, Y., Pan, X., Tang, J., Zhang, G., 2012. Occurrence and distribution of antibiotics in the Beibu Gulf, China: impacts of river discharge and aquaculture activities. Mar. Environ. Res. 78, 26-33.

Zhu, Y.-G., Johnson, T.A., Su, J.-Q., Qiao, M., Guo, G.-.X., Stedtfeld, R.D., Hashsham, S.A., Tiedje, J.M., 2013. Diverse and abundant antibiotic resistance genes in Chinese swine farms. Proc. Natl. Acad. Sci. U. S. A. 110 (9), 3435-3440.

Zhu, Y.-G., Zhao, Y., Li, B., Huang, C.-L., Zhang, S.-Y., Yu, S., Chen, Y.-S., Zhang, T., Gillings, M.R., Su, J.-Q., 2017. Continental-scale pollution of estuaries with antibiotic resistance genes. Nat. Microbiol. 2:16270. https://doi.org/10.1038/nmicrobiol.2016.270.

Zou, S., Xu, W., Zhang, R., Tang, J., Chen, Y., Zhang, G., 2011. Occurrence and distribution of antibiotics in coastal water of the Bohai Bay, China: impacts of river discharge and aquaculture activities. Environ. Pollut. 159, 2913-2920. 